\title{
Knowledge, attitude, and practice of exclusive breastfeeding among mothers in East Africa: a systematic review
}

\author{
Jean Prince Claude Dukuzumuremyi ${ }^{1}$, Kwabena Acheampong ${ }^{2}$, Julius Abesig ${ }^{2}$ and Jiayou Luo ${ }^{1 *}$ (D)
}

\begin{abstract}
Background: Exclusive breastfeeding (EBF) is recommended for the first six months of age by the World Health Organization. Mothers' good knowledge and positive attitude play key roles in the process of exclusive breastfeeding practices. In this study, we report on a systematic review of the literature that aimed to examine the status of mothers' knowledge, attitude, and practices related to exclusive breastfeeding in East Africa, so as to provide clues on what can be done to improve exclusive breastfeeding.
\end{abstract}

Methods: A systematic review of peer-reviewed literature was performed. The search for literature was conducted utilizing six electronic databases, Pub med, Web of Science, Google Scholar, Embase, Science Direct, and Cochrane library, for studies published in English from January 2000 to June 2019 and conducted in East Africa. Studies focused on mothers' knowledge, attitudes, or practices related to exclusive breastfeeding. All papers were reviewed using a predesigned data extraction form.

Results: Sixteen studies were included in the review. This review indicates that almost $96.2 \%$ of mothers had ever heard about EBF, $84.4 \%$ were aware of EBF, and $49.2 \%$ knew that the duration of EBF was the first six months only. In addition, $42.1 \%$ of mothers disagreed and $24.0 \%$ strongly disagreed that giving breast milk for a newborn immediately and within an hour is important, and $47.9 \%$ disagreed that discarding the colostrum is important. However, $42.0 \%$ of mothers preferred to feed their babies for the first six months breast milk alone. In contrast, $55.9 \%$ of them had practiced exclusive breastfeeding for at least six months.

Conclusions: Exclusively breastfeeding among our sample is suboptimal, compared to the current WHO recommendations. Thus, it is important to provide antenatal and early postpartum education and periodical breastfeeding counseling, to improve maternal attitudes and knowledge toward breastfeeding practices.

Keywords: Exclusive breastfeeding, Knowledge, Attitude, Practice, East Africa

\section{Background}

Exclusive breastfeeding (EBF) is defined as giving breast milk only to the infant, without any additional food or drink, not even water in the first six months of life, with the exception of mineral supplements, vitamins, or medicines $[1,2]$. The

\footnotetext{
*Correspondence: jiayouluo@126.com

'Department of Maternal and Child Health, Xiangya School of Public Health, Central South University, Changsha 410078, China

Full list of author information is available at the end of the article
}

World Health Organization (WHO) and the United Nation Children's Fund (UNICEF) recommend initiation of breastfeeding within the first hour after birth; exclusively breastfeed for the first six months of age and continuation of breastfeeding for up to two years of age or beyond in addition to adequate complementary foods $[3,4]$.

EBF is an important public health strategy for improving children's and mother's health by reducing child morbidity and mortality and helping to control 
healthcare costs in society [5]. Additionally, EBF is one of the major strategies which help the most widely known and effective intervention for preventing early childhood deaths. Every year, optimal breastfeeding practices can prevent about 1.4 million deaths worldwide among children under five [6]. Beyond the benefits that breastfeeding confers to the mother-child relationship, breastfeeding lowers the incidence of many childhood illnesses, such as middle infections, pneumonia, sudden infant death syndrome, diabetes mellitus, malocclusion, and diarrhea $[7,8]$. Also, breastfeeding supports healthy brain development and is associated with higher performance on intelligence tests among children and adolescents [3, 9]. In mothers, breastfeeding has been shown to decrease the frequency of hemorrhage, postpartum depression, breast cancer, ovarian and endometrial cancer, as well as facilitating weight loss $[7,10]$. The lactation amenorrhea method is an important choice for postpartum family planning $[4,10]$.

The World Health Assembly (WHA) has set a global target in order to increase the rate of EBF for infants aged 0-6 months up to at least 50\% in 2012-2025 [1]. Adherence to these guidelines varies globally, only $38 \%$ of infants are exclusively breastfed for the first six months of life [1, 11]. High-income countries such as the United States (19\%), United Kingdom (1\%), and Australia (15\%) [12], have shorter breastfeeding duration than do low-income and middle-income countries. However, even in low-income and middle-income countries, only $37 \%$ of infants younger than six months are exclusively breastfed [13]. According to recent papers in the sub-Saharan Africa region, only $53.5 \%$ of infants in east African countries were EBF for six months [14], which is way below the WHO target of 90\% [15].

In addition, a study conducted in Tanzania reported that more than $91 \%$ of mothers received healthcare in the antenatal period. However, only 39\% of pregnant women and $25 \%$ of postpartum mothers reported having received breastfeeding counseling [16], and many women perceived that the quantity of mothers' breast milk is low for a child's growth. The mothers perceived that the child is thirsty and they need to introduce herbal medicine for cultural purposes was among the important factors for early mixed feeding [16-18]. The secondary analysis of WHO Global reported that barriers of breastfeeding in low-income countries include cultural beliefs, education, and access to healthcare [19].

Mothers' good knowledge and positive attitude play key roles in the process of breastfeeding [20]. A previous study reported that mothers with higher knowledge of EBF were 5.9 times more likely to practice EBF than their counterparts (OR 5.9; 95\% CI 2.6, 13.3; $p<0.001$ ) [21] and higher scores of breastfeeding knowledge (OR 1.09; 95\% CI 1.04-1.14), attitude (OR 1.04; 95\% CI 1.00,
1.09), and practice control (OR 1.11; 95\% CI 1.02, 1.20) were associated with a higher prevalence of exclusive breastfeeding [22].

Although several studies have been conducted on the knowledge, attitude, and practice (KAP) of EBF in some African countries, to our knowledge, no systematic review has been conducted to summarize these findings in East African countries. Therefore, the following questions emerged, what is the KAP of mothers in relation to EBF described in the literature and how are these domains being evaluated? KAP investigations lead to an understanding of what a particular mother knows, thinks, and does in relation to exclusive breastfeeding.

The purpose of this review was to examine the status of mothers' KAP related to EBF in east Africa. In order to promote and support the practice of exclusive breastfeeding among mothers in east Africa and to increase the number of mothers who want to achieve the better development of children, it is also important to inform the policymakers, with an intervention that could improve knowledge, attitude, and behaviors of women regarding exclusive breastfeeding.

\section{Methods}

\section{Searching strategies}

The current systematic review was reported using the Preferred Reporting Items for Systematic Reviews and meta-analysis (PRISMA) [23]. We searched published literature using the PubMed, Web of Science, Google Scholar, Embase, Science direct, and Cochrane library databases. The search was conducted using the following keywords: exclusive breastfeeding, knowledge, attitude, practice, and East Africa. The search terms were used separately and in combination using Boolean operators like "AND" and "OR". Studies published from 1 January 2000 to 25 June 2019 were included in this study. The reference list of included studies was hand searched and screened.

\section{Eligibility criteria Inclusion criteria}

This systematic review was based on the following inclusion criteria: 1) study area: the studies exclusively done in any of the countries of East Africa (EA). EA being made by the following countries, including Rwanda, Burundi, Uganda, Kenya, Tanzania, Djibouti, Eritrea, Ethiopia, Somalia, Mozambique, Madagascar, Malawi, Zambia, Zimbabwe, Comoros, Mauritius, Seychelles, Reunion, Mayotte, South Sudan, and Sudan were selected [24], 2) publication condition: articles published in peer-reviewed journals, 3) types of studies: any types of study designs reporting the impact of knowledge, or attitude towards EBF practice, 4) language: only English publications were considered, 5) study participants: 
mothers of any age, 6) types of outcome interests. The research focused on knowledge, attitude, and practice towards exclusive breastfeeding among mothers.

\section{Exclusion criteria}

The studies focused on health professionals and articles focused on mothers with their partners were excluded. Studies reported on breastfeeding alone, not exclusive breastfeeding were also excluded, and books, thesis, dissertation, case report conference, data unavailable studies, and articles were not accessed.

\section{Selection of studies and data extraction}

All researchers independently screened titles and abstracts for eligibility. The full text was then revised to confirm an eligibility criteria match. Using a predesigned data extraction form, all investigators independently extract the following data from each study: (1) study characteristics, including the name of the primary author, publication year, the country where the study was conducted, study design, sample size, aims, methods, and instrument, (2) study assessed mothers' knowledge, attitude, and practice about EBF.

All investigators independently screened the studies according to the titles and abstracts. If the articles met the eligibility criteria, we would further read the full text to screen the study and any discrepancies between all investigators were resolved by discussion.

\section{Quality assessment}

The Newcastle Ottawa scale for cross-sectional studies quality assessment tool was adopted and used to assess the quality of each study [25]. The tool has three major sections. The first section graded from five stars focuses on the methodological quality of each study, the second section of the tool deals with the comparability of the study, and the last section deals with the outcomes and statistical analysis of each original study. All authors independently evaluated the quality of each original study using the tool, moreover; disagreements between all authors were resolved. Finally, no studies were excluded from the quality assessment and the result of quality assessment scores can found in Table 1.

\section{Data analysis}

The pooled total percentage of each variable of interest was generated from included studies. The numerator percentage was retrieved from each question and calculated using the numbers of mothers who were the respondents divided by the total sample size of the studies from those questions were reported. The total percentage was only generated for variables conducted in more than two studies.

\section{Results}

\section{Study selection}

In the first step of our search strategy and terms, 8928 studies were retrieved, from which 91 were duplicates leaving 8837 papers (Fig. 1). The titles and abstracts were screened for relevance and a further 50 papers were eliminated. The full text of the remaining 41 relevant papers was assessed to make further exclusions; 25 were excluded because the participants were not mothers, the intervention examined in studies focused on outcomes of health professionals and also not related to mothers, or knowledge, or attitude about EBF were not reported.

\section{Description of the included studies}

Summary of the studies included in this review of East Africa countries published between 2001 and 2018 were shown in Table 1. Of the studies conducted; seven were from Ethiopia [26, 30, 33, 36-39], three from Kenya [28, $29,35]$, two from Uganda [31, 32], one from Rwanda [27], two from Tanzania [34, 41], and one from South Sudan [40]. The sample sizes ranged from 90 to 640 participants. Seven studies reported knowledge, attitude, and practice [26, 27, 29, 33, 37-39], seven studies reported knowledge and practice [31, 32, 34-36, 40, 41], and two studies reported knowledge and attitude [28, 30]. However, there were no studies reported from the other east Africa countries due to lack of data. The majority of the studies assessed the knowledge of EBF through questionnaires $[27,32,34,35,40]$ and/or interviews $[26,29-31,33,36-39,41]$, and one study was focusing on group discussions [28]. The lowest and highest prevalence $(26.4,82.2 \%)$ of EBF was observed in the study conducted in Ethiopia [36, 39]. Concerning the quality of the score, the lowest score of three was found in the study conducted in Uganda [32] while the highest was eight was a study conducted in Kenya [29].

\section{Mothers' knowledge about EBF}

The mothers' knowledge in aspects of EBF is presented in Table 2; there are 20 questions about knowledge of EBF, which mainly focused on the importance of EBF and breast milk, duration of feeding, early initiation, breastfed on-demand, colostrum, the right time to start the complimentary foods, definition, benefits to mothers and babies, the danger of bottle feeding, and general knowledge about exclusive breastfeeding. The percentage of knowledge ranges from 41.4 to $97.5 \%$ with a higher percentage indicating more knowledge.

There are two questions that showed the importance of EBF, including "the importance of breastfeeding", and "breast milk alone is important for the baby in the first six months", and the right answer percentage is 97.5 and $83.8 \%$ respectively. For the duration questions; "early 
Table 1 Summary of the characteristics of studies

\begin{tabular}{|c|c|c|c|c|c|}
\hline $\begin{array}{l}\text { Author(s) } \\
\text { and } \\
\text { country }\end{array}$ & Aim & $\begin{array}{l}\text { Sample } \\
\text { size }\end{array}$ & Design & Methods/instrument & $\mathrm{QA}$ \\
\hline $\begin{array}{l}\text { Wolde } \\
\text { et al. [26] } \\
2014 \\
\text { Ethiopia }\end{array}$ & $\begin{array}{l}\text { To determine the KAP related to EBF among } \\
\text { lactating women in Bedelle town, Southwestern } \\
\text { Ethiopia }\end{array}$ & 220 & $\begin{array}{l}\text { Descriptive } \\
\text { Cross-Sectional } \\
\text { Study }\end{array}$ & $\begin{array}{l}\text { The questionnaire that was used to assess the KAP } \\
\text { with structure interviewer }\end{array}$ & $\begin{array}{l}7 / \\
10\end{array}$ \\
\hline $\begin{array}{l}\text { Jino et al. } \\
\text { [27] } 2013\end{array}$ & $\begin{array}{l}\text { To assess the KAP of urban refugee women } \\
\text { regarding the EBF in order to promote its practice }\end{array}$ & 90 & $\begin{array}{l}\text { Descriptive } \\
\text { cross-sectional }\end{array}$ & $\begin{array}{l}\text { The questionnaire that was used to determine the } \\
\text { KAP }\end{array}$ & $\begin{array}{l}6 / \\
10\end{array}$ \\
\hline
\end{tabular}

Rwanda among this group of population and increase the number of women who adhere to it for improving the development of their children.

Girard To investigate associations between indicators of

et al. [28] food insecurity and attitudes and beliefs about EBF.

2012

Kenya

Mohamed To compare the KAP on EBF between primiparous et al. [29] and multiparous mothers attending Wajir County $2018 \quad H o s p i t a l, K e n y a$, and investigated the association Kenya between maternal KA and EBF.

study

Alamirew To assess KA towards EBF among mothers et al. [30] attending antenatal care and immunization clinic in

2017

Ethiopia

Adrawa To assess information on the level of KA of EBF et al. [31] among breastfeeding mothers in the Adjumani 2018 District in the West Nile Region of Uganda.

Uganda

Petit et al. To assess the perception and knowledge on EBF [32] 2010 practice among mothers attending antenatal and Uganda infant follow up clinics in Mbarara hospital, Uganda in August 2008

Asfaw et al. To investigate the KAP towards EBF among [33] 2015 mothers who have children aged below 12 months Ethiopia and to determine factors influencing EBF practice.

Nkala et al. To assess the prevalence of EBF and its predictors in 402 [34] 2011 the Kigoma Municipality, Western Tanzania.

Tanzania

Gewa et al. To determine the relationships among mothers' [35] 2016 knowledge, outcome expectancies, normative Kenya beliefs, and cessation of EBF in rural Kenya.

Bayissa To examine the KP of women and identify et al. [36] associated factors towards EBF

2015

Ethiopia

Wana et al. To examine the KAP on EBF of childbearing women [37] 2017 in Boditi town, Southern Ethiopia

Ethiopia

Ballo et al. To investigate the KAP and determinant factors of [38] 2016 EBF on point in time data collection from women Ethiopia attended their last delivery in the health facility.

Tadele To examine KAP towards EBF among breastfeeding et al. [39] women in Mizan Aman town, South West Ethiopia

2016

Ethiopia

Warillea To determine the KP and identify factors affecting
Cross-sectional Mixed methods' to collect a combination of quantitative qualitative and quantitative data through focus and qualitative group discussion and interviews with structured and open-ended $r$ responses.

Cross-sectional The researcher and research assistants comparative administered the

study questionnaire to the sampled women in a onetime face to face interview with each mother at the $\mathrm{MCH}$ clinic at the hospital,

Descriptive A questionnaire was collected by using pretested, 6/ cross-sectional structured interview to assess knowledge and attitude towards EBF among mothers

Descriptive Interviewer administered survey questionnaires cross-sectional were used to collect quantitative data. Cross-sectional questionnaire. study.

Cross-sectional The data were collected using an interview 7/ community- method by pretested questionnaires to investigate 10 based survey the KAP

Cross-sectional A questionnaire was used to gather information 6/ study on demographic characteristics, knowledge of EBF, 10 infant feeding practices, and HIV status.

Cross-sectional A questionnaire consisting of both closed and 5/ study open-ended questions to assess breastfeeding KP 10 of EBF, outcome expectancies, social norms, and household socio-economic status and demographics as detailed below.

Cross-sectional The interviewer-administered the questionnaire to 6/ study examine KP.

Cross-sectional The data was collected using an interview 6/ study administered questionnaire with close-ended types of the question by face to face interviews with participants.

Cross-sectional Interviewed through the phone through

study structured questioner to assess KAP

Descriptive Structured interviewer-administered questionnaire 5/ cross-sectional using 'recall since birth' method was conducted in 10 Study April 2015to assess KAP

Cross-sectional A questionnaire was used to obtain information 
Table 1 Summary of the characteristics of studies (Continued)

\begin{tabular}{|c|c|c|c|c|c|}
\hline $\begin{array}{l}\text { Author(s) } \\
\text { and } \\
\text { country }\end{array}$ & Aim & $\begin{array}{l}\text { Sample } \\
\text { size }\end{array}$ & Design & Methods/instrument & $\mathrm{QA}$ \\
\hline $\begin{array}{l}\text { et al. [40] } \\
2017 \text { South } \\
\text { Sudan }\end{array}$ & $\begin{array}{l}\text { the success of EBF during their babies first } 6 \\
\text { months among women with infants now aged } \\
\text { between } 9 \text { and } 12 \text { months attending the } \\
\text { immunization and the outpatient clinics at Al-Sabah } \\
\text { Hospital, Juba }\end{array}$ & & descriptive & $\begin{array}{l}\text { on socio-demographic status, birth-related events, } \\
\text { KP to EBF, sources of breastfeeding education, and } \\
\text { family support. }\end{array}$ & 10 \\
\hline $\begin{array}{l}\text { Shirima } \\
\text { et al. [41] } \\
\text { 2001, } \\
\text { Tanzania }\end{array}$ & $\begin{array}{l}\text { To identify factors related to early infant feeding } \\
\text { practices }\end{array}$ & 640 & $\begin{array}{l}\text { Cross-sectional } \\
\text { study }\end{array}$ & $\begin{array}{l}\text { Data were collected using structured and } \\
\text { interviewer } \\
\text { administered questionnaire }\end{array}$ & $\begin{array}{l}5 / \\
10\end{array}$ \\
\hline
\end{tabular}

KAP: Knowledge, Attitude, and Practice; KP: Knowledge and Practice KA: Knowledge and Attitude; EBF: Exclusive Breastfeeding, QA: Quality Assessment

initiation, breastfed on-demand, colostrum fed immediately, know about EBF and the right time to start complimentary food", the right answer percentage is $49.2,75.8,41.4,67.984 .4$, and 81.0\%, respectively. In addition, "ever heard about EBF, EBF protects babies from illness, EBF protects mothers from pregnancy, breast milk alone is enough for an infant less than six months of life, and the danger of bottle-feeding", the right answer percentage is 96.2, 55.1, 41.7, 60.5, 61.8\% respectively. Furthermore, there are another seven questions on the range percentages from 52.2 to $96.2 \%$ (Table 2).

\section{Mothers' attitudes about EBF}

As shown in Table 3, there are 22 questions used to assess women's attitude to breastfeeding, covering respondents' attitude about early initiation, discarding the colostrum, starting complementary foods before six months are important, EBF is enough for a child for up to six months, prefer what to feed your baby for the first six months, formula feeding is more convenient than breastfeeding, EBF is beneficial to the child, breastfeeding increases mother infant-bonding, breastfed babies are healthier than fed babies, EBF is better than artificial feeding, etc.

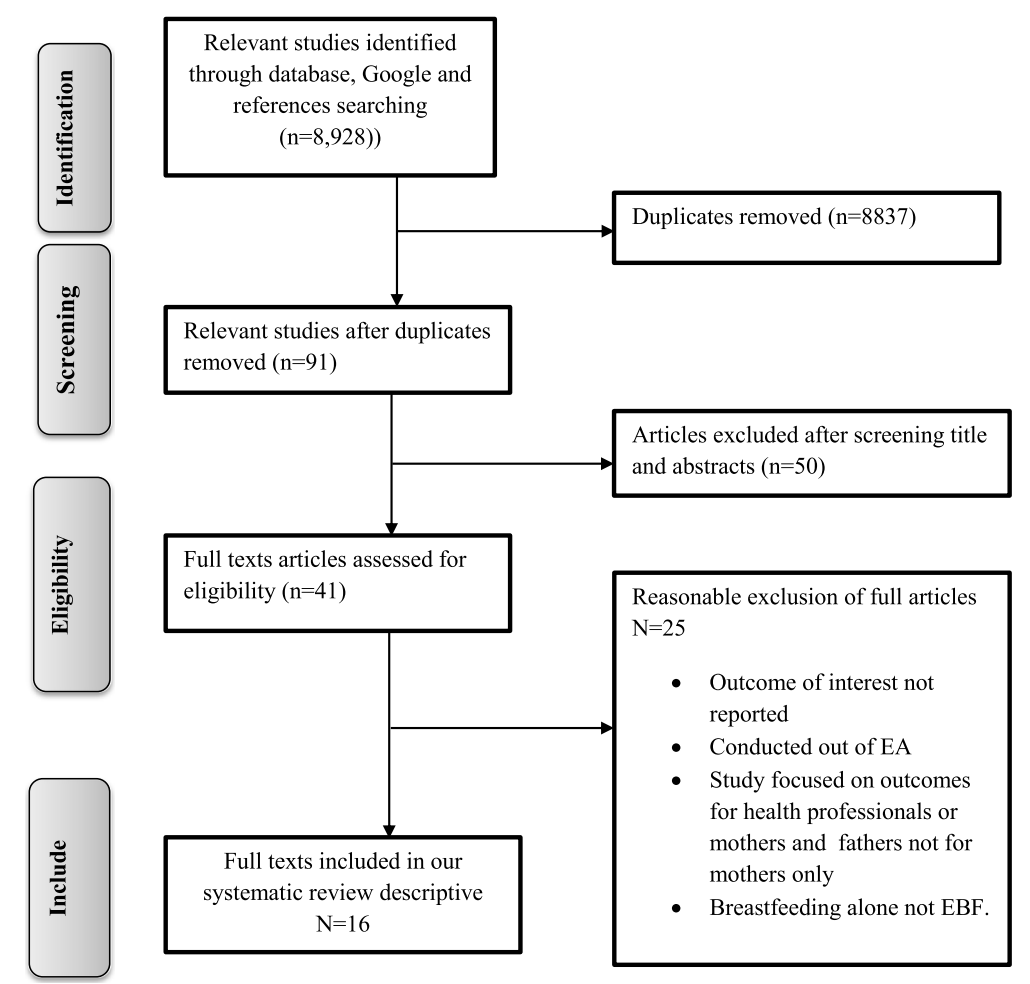

Fig. 1 PRISMA flow diagram of study selection 


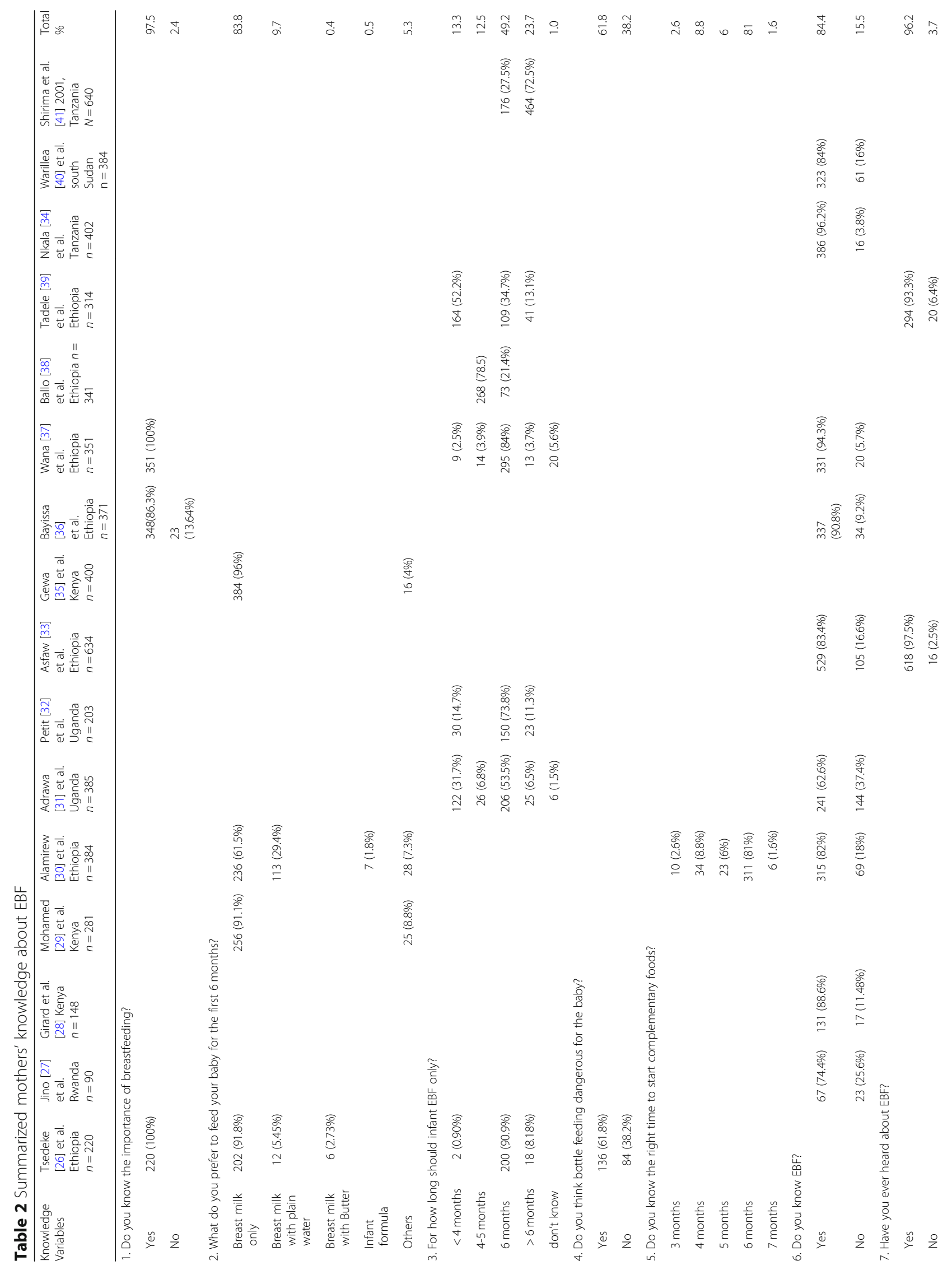




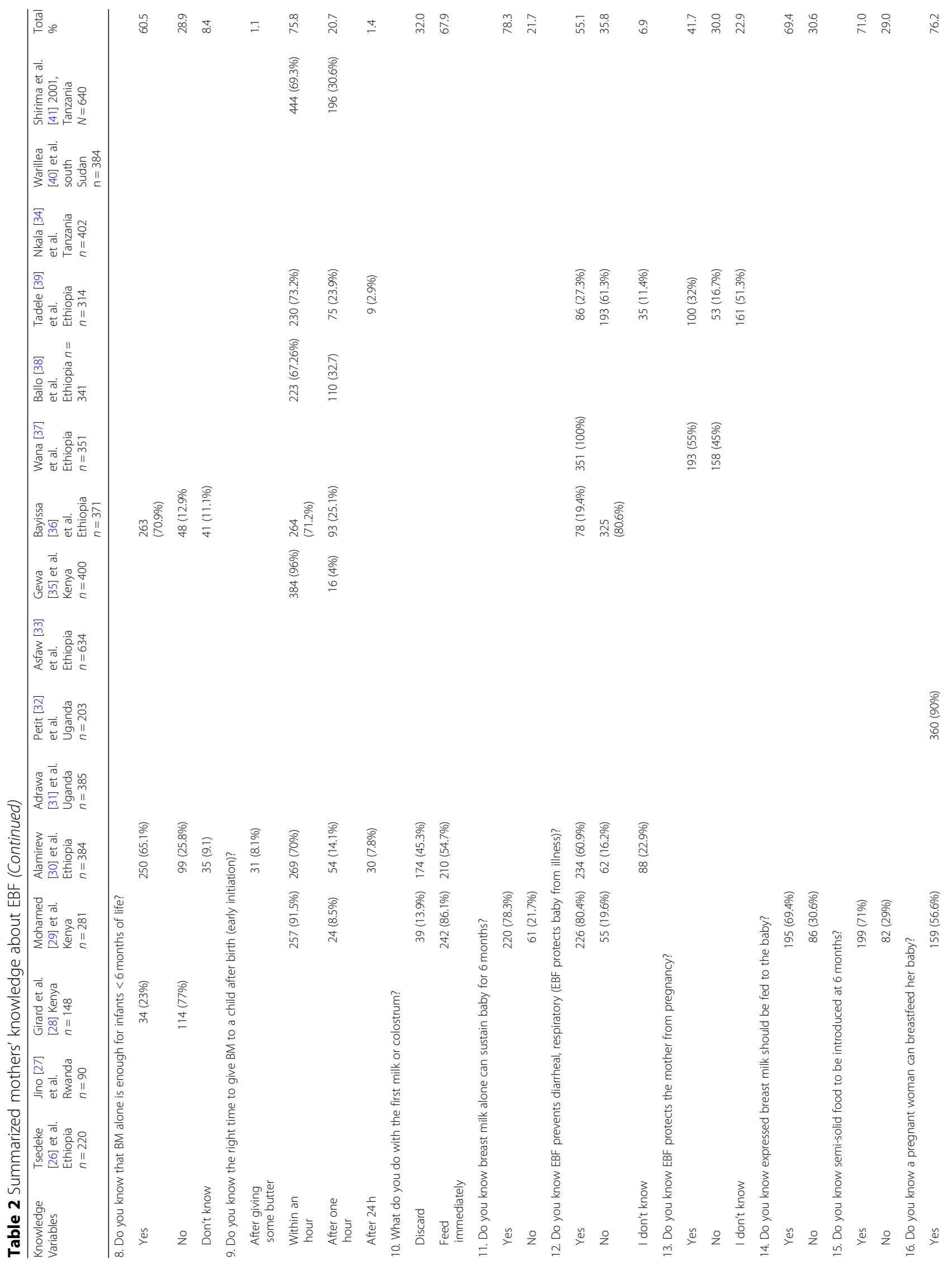




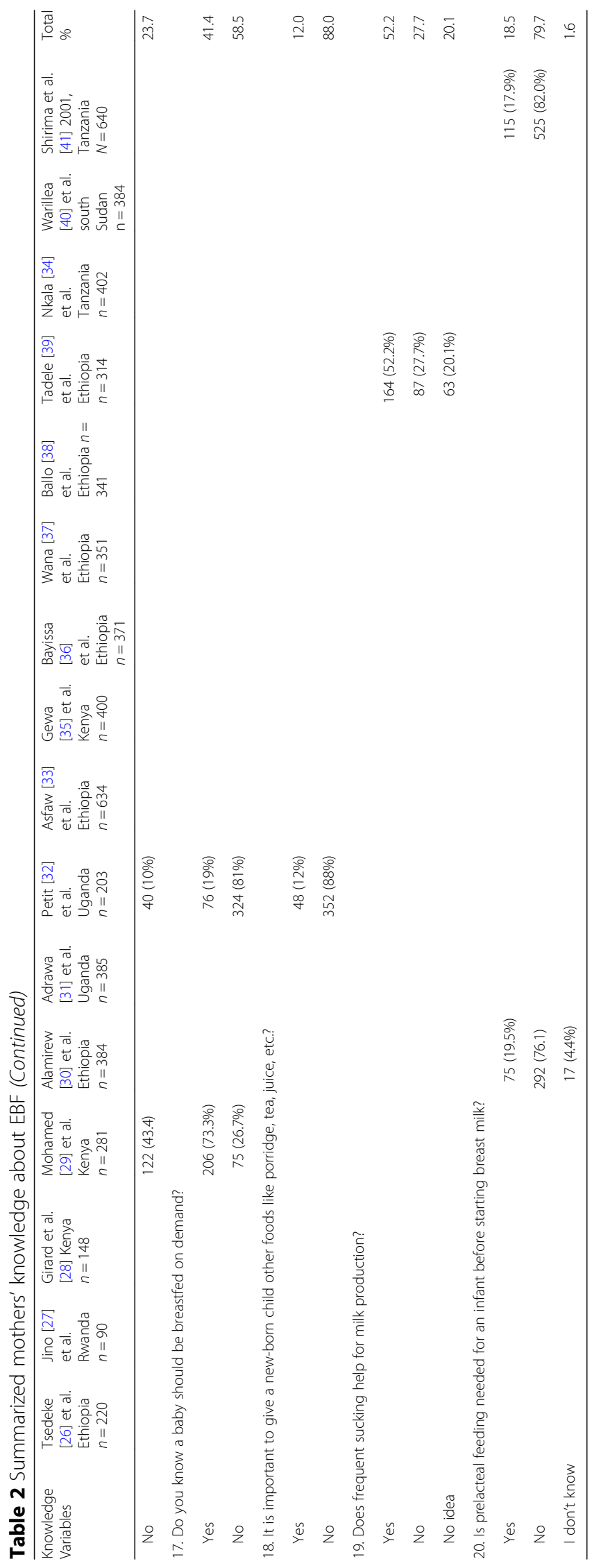


Table 3 Summarized mothers' attitudes about EBF

\begin{tabular}{|c|c|c|c|c|c|c|c|c|c|}
\hline Attitude variables & $\begin{array}{l}\text { Tsedeke [26] et al., } \\
\text { Ethiopia } \\
220\end{array}$ & $\begin{array}{l}\text { Girard [28] } \\
\text { et al. Kenya } \\
148\end{array}$ & $\begin{array}{l}\text { Mohamed [29] } \\
\text { et al., Kenya } \\
281\end{array}$ & $\begin{array}{l}\text { Alamirew } \\
{[30]} \\
\text { et al. } \\
\text { Ethiopia } \\
384\end{array}$ & $\begin{array}{l}\text { Asfaw [33] } \\
\text { et al. } \\
\text { Ethiopia }\end{array}$ & $\begin{array}{l}\text { Wana } \\
{[37]} \\
\text { et al. } \\
\text { Ethiopia } \\
351\end{array}$ & $\begin{array}{l}\text { Ballo [38] } \\
\text { et al. } \\
\text { Ethiopia } \\
384\end{array}$ & $\begin{array}{l}\text { Tadele } \\
\text { [39] } \\
\text { et al. } \\
\text { Ethiopia } \\
\mathrm{N}=314\end{array}$ & $\begin{array}{l}\text { Total } \\
\%\end{array}$ \\
\hline
\end{tabular}

1. Giving breast milk for a newborn immediately within one hour (early initiation) is important?

Strongly agree

Agree

Disagree

Strongly disagree

2. Discarding the first milk or colostrum is important?

$\begin{array}{lll}\text { Strongly agree } & 0.00 \% & 55(14.3 \%) \\ \text { Agree } & 78(35.45 \%) & 90(23.4 \%) \\ \text { Neutral } & 2(0.91 \%) & 130(33.9 \%) \\ \text { Disagree } & 140(63 \%) & 109(28.4 \%)\end{array}$

3. Only breast milk may not be sufficient for 3 months' child?

Agree

Disagree

$153(54.4 \%)$

$108(38.4 \%)$

Strongly disagree

$0.00 \%$

$20(7.1 \%)$

Neutral

4. Do you think of starting complementary foods before 6 months is important?

Strongly agree

Agree

Disagree

Strongly disagree

5. What do you prefer to feed your baby for the first 6 months?

$\begin{array}{ll}\text { Breast milk alone } & 162(73.64 \%) \\ \begin{array}{l}\text { Breast milk with } \\ \text { formula }\end{array} & 5(2.27 \%) \\ \begin{array}{l}\text { Breast milk with cow } \\ \text { milk }\end{array} & 50(22.72 \%) \\ \text { Others } & 3(1.37 \%)\end{array}$

. Do you Believe that EBF is beneficial to the Childs?

$\begin{array}{lll}\text { Agree } & 192(87.27 \%) & 267(95 \%) \\ \text { Disagree } & 28(12.73 \%) & 11(4 \%) \\ \text { Neutral } & & 3(1 \%)\end{array}$

8. The age of the mother influences her ability to EBF?

Agree

211 (75\%)

56 (14.6\%)

87 (22.6\%)

150 (39.1\%)

91 (23.7\%)

$46(12 \%)$

61 (15.9\%)

169 (44\%)

108 (28.1\%)

$92(24 \%)$

$292(76 \%)$

Disagree

41 (14.6\%)

Neutral

29 (10.32\%)

234 (83.3\%)

$337(87.7 \%) \quad 182$

Neutral

31 (11\%)

$16(5.6)$
48.8

91.6

75.0

(58\%)

45 (11.76\%) 79

(25.1\%) 
Table 3 Summarized mothers' attitudes about EBF (Continued)

\begin{tabular}{|c|c|c|c|c|c|c|c|c|c|}
\hline Attitude variables & $\begin{array}{l}\text { Tsedeke [26] et al., } \\
\text { Ethiopia } \\
220\end{array}$ & $\begin{array}{l}\text { Girard [28] } \\
\text { et al. Kenya } \\
148\end{array}$ & $\begin{array}{l}\text { Mohamed [29] } \\
\text { et al., Kenya } \\
281\end{array}$ & $\begin{array}{l}\text { Alamirew } \\
{[30]} \\
\text { et al. } \\
\text { Ethiopia } \\
384\end{array}$ & $\begin{array}{l}\text { Asfaw [33] } \\
\text { et al. } \\
\text { Ethiopia }\end{array}$ & $\begin{array}{l}\text { Wana } \\
{[37]} \\
\text { et al. } \\
\text { Ethiopia } \\
351\end{array}$ & $\begin{array}{l}\text { Ballo [38] } \\
\text { et al. } \\
\text { Ethiopia } \\
384\end{array}$ & $\begin{array}{l}\text { Tadele } \\
\text { [39] } \\
\text { et al. } \\
\text { Ethiopia } \\
\mathrm{N}=314\end{array}$ & $\begin{array}{l}\text { Total } \\
\%\end{array}$ \\
\hline
\end{tabular}

10. Breast milk is more easily digested than formula?

$\begin{array}{lll}\text { Agree } & 228(81.1 \%) & 81.1 \\ \text { Disagree } & 34(12 \%) & 12.0 \\ \text { Neutral } & 19(6.7 \% & 6.7\end{array}$

11. Do you think EBF prevent pregnancy?

$\begin{array}{ll}\text { Agree } & 193 \\ & \\ \text { Disagree } & (55 \%) \\ & 132\end{array}$

Don't know

12. Do you think breastfeeding limits activity?

$\begin{array}{ll}\text { Agree } & 53 \\ \text { Disagree } & 298 \\ & (85 \%)\end{array}$

Don't know

13. Do you think BF has a relation with pain and Cancer?

Agree

Disagree

14. Formula feeding is more convenient than breastfeeding?

Agree

Disagree

Neutral

15. Does breastfeeding increases mother-infant bonding?

Agree

Disagree

Neutral

16. Women need adequate food for EBF for 6 months?
Agree
$62(42 \%)$
Disagree
$86(58 \%)$

Neutral

17. Women who EBF for 6 months will have problems?
Agree
86 (58\%)
Disagree

18. Infants, that EBF for 6 months will have problems?

$\begin{array}{ll} & 76(51.4 \%) \\ \text { Agree } & 72(48.6 \%)\end{array}$

19. Do you think that EBF is better than artificial feeding? 
Table 3 Summarized mothers' attitudes about EBF (Continued)

\begin{tabular}{|c|c|c|c|c|c|c|c|c|c|}
\hline Attitude variables & $\begin{array}{l}\text { Tsedeke [26] et al., } \\
\text { Ethiopia } \\
220\end{array}$ & $\begin{array}{l}\text { Girard [28] } \\
\text { et al. Kenya } \\
148\end{array}$ & $\begin{array}{l}\text { Mohamed [29] } \\
\text { et al., Kenya } \\
281\end{array}$ & $\begin{array}{l}\text { Alamirew } \\
\text { [30] } \\
\text { et al. } \\
\text { Ethiopia } \\
384\end{array}$ & $\begin{array}{l}\text { Asfaw [33] } \\
\text { et al. } \\
\text { Ethiopia }\end{array}$ & $\begin{array}{l}\text { Wana } \\
\text { [37] } \\
\text { et al. } \\
\text { Ethiopia } \\
351\end{array}$ & $\begin{array}{l}\text { Ballo [38] } \\
\text { et al. } \\
\text { Ethiopia } \\
384\end{array}$ & $\begin{array}{l}\text { Tadele } \\
\text { [39] } \\
\text { et al. } \\
\text { Ethiopia } \\
\mathrm{N}=314\end{array}$ & $\begin{array}{l}\text { Total } \\
\%\end{array}$ \\
\hline & & & & & & & & $(23.8 \%)$ & \\
\hline Don't know & & & & & & & & $9(3.2 \%)$ & 3.2 \\
\hline \multicolumn{10}{|c|}{ 20. Do you agree that only EBF is enough for a child for up to 6 months? } \\
\hline Agree & & $34(23 \%)$ & & & & & & $\begin{array}{l}186 \\
(59.3 \%)\end{array}$ & 47.6 \\
\hline Disagree & & $114(77 \%)$ & & & & & & $\begin{array}{l}128 \\
(40.7 \%)\end{array}$ & 52.3 \\
\hline \multicolumn{10}{|c|}{ 21. Why do you encourage exclusive breastfeeding? } \\
\hline $\begin{array}{l}\text { Prevent infection and } \\
\text { infant death** }\end{array}$ & & & & & $421(68.1 \%)$ & & & & 68.1 \\
\hline $\begin{array}{l}\text { Improve infant's } \\
\text { strength* }\end{array}$ & & & & & $228(36.9 \%)$ & & & & 36.9 \\
\hline Cost-effective* & & & & & $121(19.6 \%)$ & & & & 19.6 \\
\hline \multicolumn{10}{|c|}{ 22. Do you encourage mothers to EBF their infant? } \\
\hline Yes & & & & & $618(97.5 \%)$ & & & & 97.5 \\
\hline No & & & & & $16(2.5 \%)$ & & & & 2.5 \\
\hline
\end{tabular}

*Sum larger than hundred due to multiple answers

There are three questions that showed the importance of EBF, which focused on "importance of early initiation, discarding the colostrum, and starting complementary foods before six months", the right answer percentage $28.9,47.9$, and $72.1 \%$, respectively. In addition, for "EBF is enough for a child up to six months, prefer to feed your baby for the first six months, breastfeeding increases mother infant-bonding, EBF is beneficial to the child, breastfed babies are healthier than fed babies, formula feeding is more convenient than breastfeeding, and EBF is better than artificial feeding", the right answers percentage 47.6, 42.0, 48.6, 91.61, 74.1, 45.8, and 73.0\%, respectively. In addition, 12 questions are the range percentages from 42 to $97.5 \%$.

\section{Mothers' practices about EBF}

As shown in Table 4, there are five questions about practices EBF which focused on initiation, breast on-demand, exclusive breastfeeding only, colostrum, and prelacteal food. Most of the mothers (72.9\%) had initiated breastfeeding within one hour after delivery. However, only $15.8 \%$ of mothers were breastfeeding on demand. Besides that, only $55.9 \%$ had exclusively breastfed their children for the first six months and the majority of mothers, $79.5 \%$, had given colostrum. Furthermore, only $31.6 \%$ had given prelacteal food for their newborn babies.

\section{Source of information about EBF}

Table 5 shows the source of information about exclusive breastfeeding. The mothers indicated that they mainly acquired their breastfeeding knowledge from health institutions $67.8 \%$, mass media $13.1 \%$, husband $2.6 \%$, and friends $1.4 \%$.

\section{Discussion \\ Knowledge}

This study has synthesized from the findings of 15 studies that examined the mothers' knowledge, attitudes, and practices about exclusive breastfeeding in East Africa. Most of the best answers on knowledge range from 40.1 to $97.6 \%$ in mothers regarding exclusive breastfeeding. The mothers' knowledge of EBF was generally fair, even though some notable gaps were recognized. According to the Food Agricultural and Organization (FAO) guidelines thresholds suggestive of nutrition intervention, a knowledge score of $\leq 70 \%$ is considered urgent for nutrition intervention. All mothers who scored $>70 \%$ in the knowledge test were considered to have a high level of knowledge and those scoring $\leq 70 \%$ were considered as having a low level of knowledge [42].

The results of this study indicate that mothers with a high level of knowledge about the importance of exclusive breastfeeding know that only breast milk is nutritionally important for the baby in the first six months, the right time to give breast milk to the child within one hour after birth. This result was similar to the previous studies conducted in Ghana [21] and Brazil [43]. In addition to gaps in mothers' knowledge of EBF, the results of this study indicate that most mothers also had inadequate knowledge of duration of feeding, colostrum, 


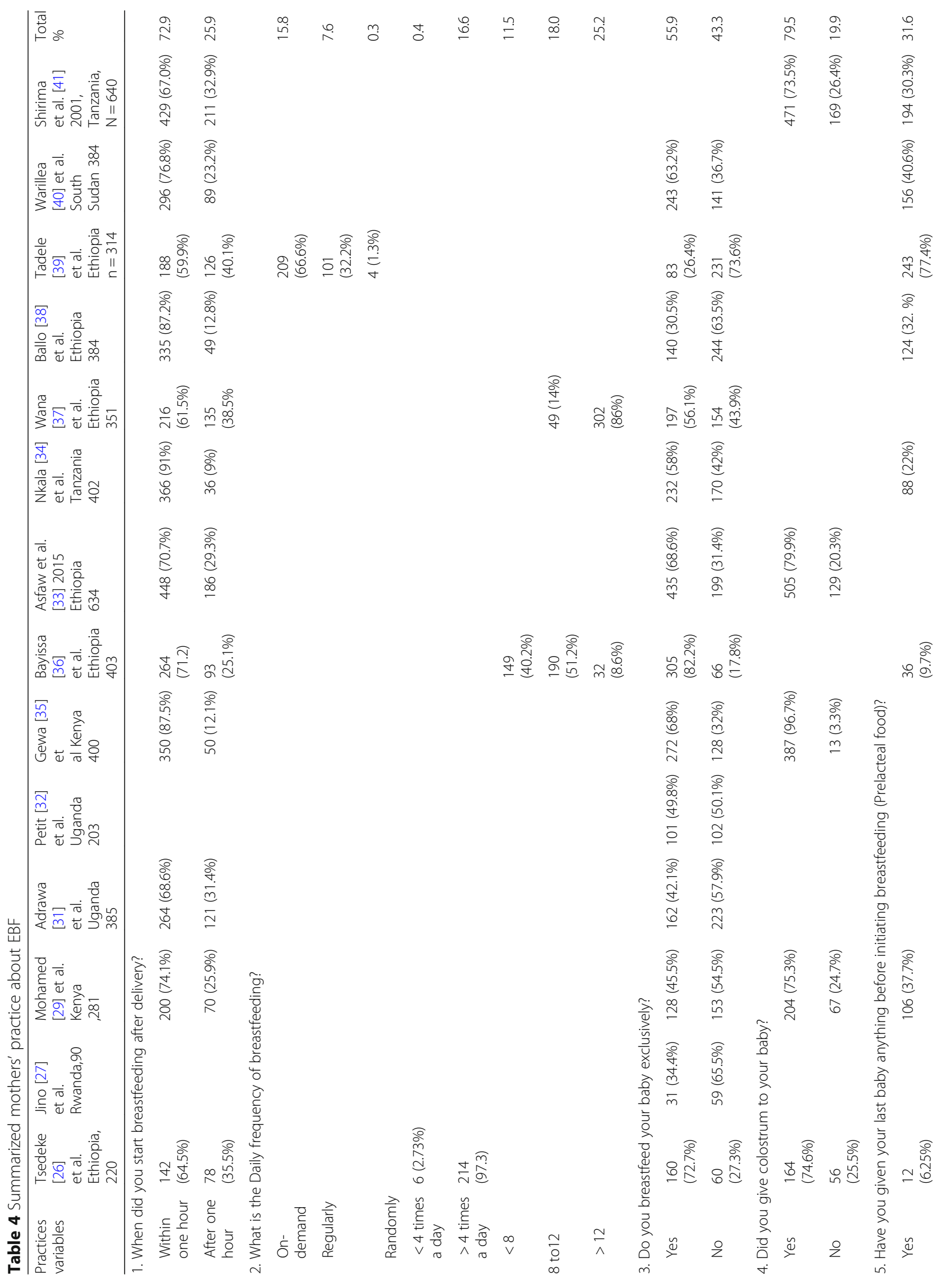




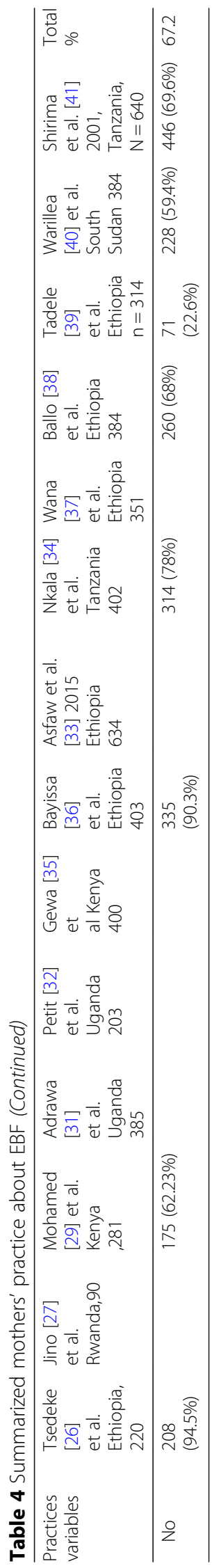


Table 5 Summarized the source of information

\begin{tabular}{|c|c|c|c|c|c|c|c|c|c|}
\hline $\begin{array}{l}\text { What is your source of } \\
\text { information }\end{array}$ & $\begin{array}{l}\text { Jino } \\
\text { et al. } \\
\text { Rwanda } \\
90 \text { [27] }\end{array}$ & $\begin{array}{l}\text { Alamirew et al. } \\
\text { Ethiopia } 314 \text { [30] }\end{array}$ & $\begin{array}{l}\text { Asfaw } \\
\text { et al. } \\
\text { Ethiopia } \\
618 \text { [33] }\end{array}$ & $\begin{array}{l}\text { Adrawa et al. } \\
\text { Uganda } 385 \text { [31] }\end{array}$ & $\begin{array}{l}\text { Tadele } \\
\text { et al. } \\
\text { Ethiopia } \\
350 \text { [39] }\end{array}$ & $\begin{array}{l}\text { Tsedeke } \\
\text { et al. } \\
\text { Ethiopia } \\
220 \text { [26] }\end{array}$ & $\begin{array}{l}\text { Bayissa } \\
\text { et al. } \\
\text { Ethiopia } \\
371 \text { [36] }\end{array}$ & $\begin{array}{l}\text { Ballo } \\
\text { et al. } \\
\text { Ethiopia } \\
384 \\
{[38]}\end{array}$ & Total\% \\
\hline Friends & $1(1.4 \%)$ & $10(3.1 \%)$ & & & 29 (9.3\%) & & & & 1.4 \\
\hline Mass media & $2(2.8 \%)$ & 59 (18.79\%) & & & $63(20 \%)$ & 64 (29.1\%) & $\begin{array}{l}171 \\
(46.0 \%)\end{array}$ & & 13.1 \\
\hline Health institution & $\begin{array}{l}65 \\
(90 \%)\end{array}$ & 255 (81.21\%) & $\begin{array}{l}559 \\
(90.5 \%)\end{array}$ & 298 (95.8\%) & $\begin{array}{l}197 \\
(62.7 \%)\end{array}$ & $\begin{array}{l}146 \\
(66.36 \%)\end{array}$ & $\begin{array}{l}107 \\
(28.8 \%)\end{array}$ & $\begin{array}{l}224 \\
(59.7)\end{array}$ & 67.8 \\
\hline Husband & $1(1.4 \%)$ & & $59(9.06 \%)$ & 13 (4.18\%) & & & & & 2.6 \\
\hline Books & & & & & & 08 (3.64\%) & & & \\
\hline Others sources & $3(4.2 \%)$ & & & & $25(8 \%)$ & 02 (0.90\%) & $25.0 \%$ & $\begin{array}{l}160 \\
(40.3)\end{array}$ & 7.6 \\
\hline
\end{tabular}

breastfed on-demand, benefits to mothers and babies, the danger of bottle-feeding, compared to the studies conducted in Italy [44], China [20], and India [45]. Therefore, these gaps in maternal knowledge should be taken into consideration for future interventions designed by health workers, policymakers, and health educators who should make a conscious effort to explain the benefits of breast milk, breastfeed on-demand, and colostrum initiation immediately after birth. Furthermore, the danger of bottle-feeding should emphasise that it is unsafe for the child since it can cause childhood infections like vomiting, diarrhea diseases.

\section{Attitudes}

Our study also examined mothers' attitudes about EBF in East Africa. Basically, positive maternal attitudes toward breastfeeding are associated with continuing to breastfeed longer and having a greater chance of successful breastfeeding. Besides, mothers with a positive attitude toward breastfeeding were likely to exclusively breastfeed their infants. According to the FAO guidelines thresholds suggestive of nutrition intervention, an attitude score of $\leq 70 \%$ is considered urgent for nutrition intervention. All mothers who scored $>70 \%$ in the attitude test were considered to have a positive attitude and those scoring $\leq 70 \%$ were considered to be less positive [42]. The results of this study indicate that few mothers had a positive attitude towards exclusive breastfeeding such as starting complementary foods after six months and belief that EBF is beneficial to the child and better than artificial feeding.

However, most mothers disagreed with the fact that giving breast milk for newborn colostrum immediately and within an hour is important, EBF is enough for a child up to six months, to feed their baby for the first six months, breastfeeding increases mother infant-bonding, breastfed babies are healthier than fed babies, formula feeding is more inconvenient than breastfeeding. The results of this study indicate that mothers had the lowest level of attitude about exclusive breastfeeding, and the findings were similar to the studies conducted in Vietnam [46], India [47], Mexico [48], China [20], Saudi Arabia [49]. The previous studies conducted in East Africa by Maonga et al. [16] and Arts, $M$ et al. [50] reported that other cultural beliefs mentioned "baby boy" need solid foods immediately because they make them strong and healthy, and if a child is breastfed on breast milk alone for six months, the bones get weak. This barrier was probably the consequence of inadequate knowledge and awareness of ensuring that mothers should exclusively breastfeed during first six months of their babies' lives, and indicates that future breastfeeding promotion programs should focus on improving this knowledge and attitude, and providing more support for mothers. Thus the fact that East Africa and nongovernment organizations have joined and established platforms to address the gaps and collectively finding the solutions for improving the exclusive breastfeeding and sustain its positive health impacts in particular at both, health facilities and community level and to work closely with the media as the main channel to mobilize the awareness. It is so important to change their attitude from negative to positive.

\section{Practices}

The findings of this study show the practices of mothers about exclusive breastfeeding. Accordingly, the studies conducted in East Africa reported factors affecting actualization of the WHO breastfeeding recommendations "poverty, livelihood and living conditions; early and single motherhood; poor social and professional support; commercial sex work, poor knowledge, myths and misconceptions; HIV and unintended pregnancies, the perception that mothers' breast milk is insufficient for child's growth, child being thirsty and the need to 
introduce herbal medicine for cultural reasons" $[16,18$, $50,51]$.

The results of this survey indicated that most of the mothers have breastfed their children, but only 55.9\% of mothers had exclusively breastfed their child for the first six months, even though most mothers have heard of EBF and consider it important for the health of the women and the baby. This study findings were higher compared with studies conducted in the developed countries like Brazil 19\% [52], in China 6.2\% [53], in Italy $33.3 \%$ [44]. The WHA global target is $50 \%$ [1] but it was lower compared to the EBF of $90 \%$ as recommended by the WHO [15]. The majority of mothers $79.5 .0 \%$ had given colostrum, this finding was similar to a study conducted in Nepal where 83.3\% of children received colostrum [54]. Most of the mothers, $72.9 \%$, had initiated breastfeeding within one hour after delivery, this result was not matching the recommendations of $\mathrm{WHO}$ and this result was highest with secondary analysis of the WHO Global Survey, $57.6 \%$ of mothers initiating breastfeeding within one hour after birth [19]. Our study was lower than the prevalence of other studies conducted in China 93.6\% [53] and in India 95\% [55]. This value indicates that healthcare providers who care for mothers should increase their efforts to promote EBF and that there is a need for public policies which that ensure the living and working conditions of women are compatible with exclusive breastfeeding.

Good feeding practice is important for the health and nutritional status of children, which in turn has dire consequences for their mental and physical development and it is important for mothers as well. Early suckling motivates the release of prolactin, which supports the production of milk, and oxytocin, which is accountable for the ejection of milk. It also stimulates contraction of the uterus after childbirth and reduces postpartum hemorrhage [56].

According to the source of information about EBF, $67.8 \%$ of mothers reported that the main source of information about EBF was the health institutions and mass media (13.1\%). This result was higher than the study conducted in India $42.5 \%$ of health workers [55], however, our result is not great so there is the need to motivate health professionals to do more education on exclusive breastfeeding. Previous studies demonstrated that motivation by healthcare workers was a stronger predictor to increase knowledge, or change attitudes, and practices favorable to breastfeeding and that for successful initiation and maintenance of breastfeeding; mothers need encouragement and support, not only from their relatives and communities but also from the health system $[20,57]$.

\section{Limitations of the study}

This systematic review has several limitations, the first limitation of this study was only English articles were considered and there may be other studies published in other languages. Relevantly, almost all studies included in this review were cross-sectional in nature. As a result, the confounding variables might be affected by other confounding variables; moreover, the majority of the studies included in this study had a small sample size, therefore these factors could generalize reports. However, most of the studies were conducted in Ethiopia, in this country socio-economic is highest compared to others, meaning the generalizability of measures to other countries cannot be assumed. In addition to that, the numerator and denominator used in the included studies were only based on the sample size of the studies which is absolutely not representatives of the population from which those studies were conducted. Furthermore; this review represented only studies reported from six countries and therefore we could not generalize our findings across EA. The country may be underrepresented due to the limited number of studies included. Another limitation was that reliability and validity to assess the outcome of mothers' EBF knowledge and attitude were not presented in all studies.

\section{Conclusions}

Exclusive breastfeeding among our sample is suboptimal, compared to the current WHO recommendations. In addition, there are relatively unfavorable levels of knowledge and a less positive attitude of EBF as compared to the FAO guidelines, in fact, the observed EBF practices across all included studies were statistically found to be $55.9 \%$, which is absolutely below the FAO and WHO recommendations. The results of this study are critically important, that as they are addressing the gap in the EBF segment and sensitively show evidence for areas where urgent interventions are needed. Moreover, these results also inform policymakers of different countries in East Africa where they can respond and integrate EBF programs within their community health system. It also identifies the need for the workforce to encourage mothers to attend antenatal and postnatal care to improve EBF practice. It also shows that educational strategies are important to improve and correct mothers' knowledge, attitudes, beliefs, and sociocultural norms about EBF. We suggest that all levels of healthcare workers should be involved with EBF education. To promote well-baby visits, antenatal and early postpartum education, and also during home visits by community health workers, should improve maternal knowledge and attitudes toward breastfeeding practice. 


\section{Abbreviations}

EBF: Exclusive Breastfeeding; WHO: World Health Organization; UNICEF: United Nation Children's Fund; WHA: World Health Assembly; KAP: Knowledge, Attitude, and Practice; PRISMA: Preferred Reporting Items for Systematic Reviews and meta-analysis; EA: East Africa; FAO: Food and Agriculture Organization; KA: Knowledge Attitude; KP: Knowledge Practice

\section{Acknowledgments}

We would like to acknowledge the authors who conducted and published the original studies.

\section{Author details}

DCJP ${ }^{1}$ is a master student in the Department of Maternal and Child Health, Xiangya School of Public health, Central South University, Changsha, China. $\mathrm{KA}^{2}$ is a Ph.D. student in the Department of Epidemiology and health statistics, Xiangya School of Public health, Central South University, Changsha, China, and a graduate from the School of Postgraduate Studies, Adventist University of Africa, Nairobi, Kenya.

$\mathrm{JA}^{2}$ is a master student in the Department of Epidemiology and health statistics, Xiangya School of Public health, Central South University, Changsha, China.

$\mathrm{JL}^{*}$ is a Professor and Dean of the Maternal and Child Health Department at the Xiangya School of Public Health, Central South University, Changsha, China.

\section{Authors' contributions}

DCJP: Searched, analyzed, interpreted the data used in the manuscript, and was a major contributor in writing the manuscript. KA and JA: Searched, critically analyzed the manuscript for scientific logic and reasoning. JL: Reviewed the manuscript and approved the final version for submission.

\section{Funding}

National Natural Foundation of China (grant \#: 81172680).

\section{Availability of data and materials}

All data generated or analyzed during this study are included in this published article.

\section{Ethics approval and consent to participate}

Not applicable.

\section{Consent for publication}

Not applicable.

\section{Competing interests}

The authors declare that they have no competing interests in this study.

\section{Author details}

1Department of Maternal and Child Health, Xiangya School of Public Health, Central South University, Changsha 410078, China. ${ }^{2}$ Department of Epidemiology and Health Statistics, Xiangya School of Public Health, Central South University, Changsha 410078, China.

\section{Received: 1 November 2019 Accepted: 29 July 2020}

Published online: 14 August 2020

\section{References}

1. WHO.WHA Global Nutrition Targets 2025: Breastfeeding Policy Brief 2014 http://www.who.int/nutrition/topics/globaltargets_breastfeeding_policybrief. pdf.

2. Hossain M, Islam A, Kamarul T, Hossain G. Exclusive breastfeeding practice during first six months of an infant's life in Bangladesh: a country based cross-sectional study. BMC Pediatr. 2018;18:93

3. UNICEF. Breastfeeding: A Mother's Gift, for Every Child .2018.UNICEF: United Nations Children's Fund. https://www.unicef.org/publications/index_102824. html. Accessed 23 Jun 1019.

4. Idris SM, Tafang AGO, Elgorashi A. Factors influencing exclusive breastfeeding among mother with infant age 0-6 months. Internationa Journal of Science and Research. 2015;4(8):28-33.
5. Al-Binali AM. Breastfeeding knowledge, attitude, and practice among school teachers in Abha female educational district, southwestern Saudi Arabia. Int Breastfeed J. 2012;7:10.

6. Sinshaw Y, Ketema K, Tesfa M. Exclusive breastfeeding practice and associated factors among mothers in Debre Markos town and Gozamen district, east Gojjam zone, north West Ethiopia. Journal of Food and Nutrition Sciences. 2015;3(5):174-9.

7. Holtzman $\mathrm{O}$, Usherwood T. Australian general practitioners' knowledge, attitudes, and practices towards breastfeeding. PLoS One. 2018;13(2): e0191854.

8. Ogbo FA, Nguyen H, Naz S, Agho KE, Page A. The association between infant and young child feeding practices and diarrhoea in Tanzanian children. Trop Med Health. 2018:46:2.

9. Victora CG, Horta BL, Mola CL, Quevedo L, Pinheiro RT, Gigante DP, et al. Association between breastfeeding and intelligence, educational attainment, and income at 30 years of age: a prospective birth cohort study from Brazil. Lancet Glob Health. 2015:3:e199-205.

10. Saadehl R, Benbouzid D. Breastfeeding and child-spacing: importance of information collection for public health policy. WHO. 1990;68(5):625-63.

11. Hawley NL, Rosen RK, Strait AE, Raffucci G, Holmdahl I, Freeman JR, et al. Mothers' attitudes and beliefs about infant feeding highlight barriers to exclusive breastfeeding in American Samoa. Women Birth. 2015;28:e80-6.

12. Skouteris $H$, Nagle $C$, Fowler $M$, Kent $B$, Sahota $P$, Morris $H$. Interventions designed to promote exclusive breastfeeding in high-income countries: a systematic review. Breastfeed Med. 2014;9(3):113-27.

13. Victora CG, Bahl R, Barros AJD, França GVA, Horton S, Krasevec J, et al. Breastfeeding in the 21st century: epidemiology, mechanisms, and lifelong effect. Lancet. 2016:387:475-90.

14. Issaka Al, Agho KE, Renzaho AMN. Prevalence of key breastfeeding indicators in 29 sub-Saharan African countries: a meta-analysis of demographic and health surveys (2010-2015). BMJ Open 2017, 7:e014145.

15. Jahanpour O, Msuya SE, Todd J, Stray-Pedersen B, Mgongo M. Increasing trend of exclusive breastfeeding over 12 years period (2002-2014) among women in Moshi. Tanzania BMC Pregnancy Childbirth. 2018;18:471.

16. Maonga AR, Mahande MJ, Damian JD, Msuya SE. Factors affecting exclusive breastfeeding among women in Muheza district Tanga northeastern Tanzania: a mixed method community based study. Matern Child Health J. 2016;20:77-87.

17. Setegn T, Belachew T, Gerbaba M, Deribe K, Deribew A, Biadgilign S. Factors associated with exclusive breastfeeding practice among mothers in Goba. South East Ethiopia: A cross-sectional study Int Breastfeed J. 2012;7:17.

18. Mututho LN, Kiboi WK, Mucheru PK. Factors associated with exclusive breastfeeding in Kenya: a systematic review. International Journal of Community Medicine and Public Health. 2017:4(12):4358-62.

19. Takahashi K, Ganchimeg T, Ota E, Vogel JP, Souza JP, Laopaiboon M, et al. Prevalence of early initiation of breastfeeding and determinants of delayed initiation of breastfeeding: secondary analysis of the WHO global survey. Sci Rep. 2017:7:44868.

20. Hamze L, Mao J, Reifsnider E. Knowledge and attitudes towards breastfeeding practices: a cross-sectional survey of postnatal mothers in China. Midwifery. 2019;74:68-75.

21. Mogre V, Dery M, Gaa PK. Knowledge, attitudes, and determinants of exclusive breastfeeding practice among Ghanaian rural lactating mothers. Int Breastfeed J. 2016;11:12

22. Zhang Z, Zhu Y, Zhang L, Wan H. What factors influence exclusive breastfeeding based on the theory of planned behaviour. Midwifery. 2018; 62:177-82.

23. Yang SF, Salamonson Y, Burns E, Schmied V. Breastfeeding knowledge and attitudes of health professional students: a systematic review. Int Breastfeed J. 2018;13:8.

24. East African Countries 2020 - World Population Review. https:// worldpopulationreview.com/Countries/East-african-countries. Accessed 10 Apr 2020

25. Newcastle Ottawa scale for cross-sectional studies. 2019. https:// wellcomeopenresearch.s3.amazonaws.com > supplementary. Accessed 24 Jul 2019.

26. Wolde T, Diriba G, Wakjira A, Misganu G, Negesse G, Debela H, et al. Knowledge, attitude, and practice of exclusive breastfeeding among lactating mothers in Bedelle town, southwestern Ethiopia: descriptive crosssectional study. ResearchGate. 2014;6(11):91-7. 
27. Jino GB, Munyanshongore C, Birungi F. Knowledge, attitudes, and practices of exclusive breastfeeding of infants aged 0-6 months by urban refugee women in Kigal. Rwanda Med J. 2013;70:7-10.

28. Girard AW, Cherobon A, MbuguaS MEK, Amin A, Sellen DW. Food insecurity is associated with attitudes towards exclusive breastfeeding among women in urban Kenya. Matern Child Nutr. 2012;8:199-214

29. Mohamed MJ, Ochola S, Owino VO. Comparison of knowledge, attitudes, and practices on exclusive breastfeeding between primiparous and multiparous mothers attending Wajir District hospital, Wajir County. Kenya: a cross-sectional analytical study Int Breastfeed J. 2018;13:11.

30. Alamirew MW, Bayu NH, Tebeje NB, Kassa SF. Knowledge and attitude towards exclusive breastfeeding among mothers attending antenatal and immunization clinic at Dabat health center, Northwest Ethiopia: a crosssectional institution based study. Nurs Res Pract. 2017;9.

31. Adrawa AP, Opi D, Candia E, Vukoni E, Kimera I, Sule I, et al. Assessment of knowledge and practices of breastfeeding amongst the breastfeeding mothers in Adjumani. West Nile East African Medical Journal. 2016;93(11): 576-81.

32. Petit Al. Perception and knowledge on exclusive breastfeeding among women attending antenatal and postnatal clinics: a study from Mbarara hospital, Uganda, august 2008. Tanzania Medical Students' Association. 2010;16:1.

33. Asfaw MM, Argaw MD, Kefene ZK. Factors associated with exclusive breastfeeding practices in Debre Berhan district, Central Ethiopia: a crosssectional community-based study. Int Breastfeed J. 2015;10:23.

34. Nkala TE, Msuya SE. Prevalence and predictors of exclusive breastfeeding among women in Kigoma region. Western Tanzania: a community based cross-sectional study Int Breastfeed J. 2011;6:17.

35. Gewa CA, Chepkemboi J. Maternal knowledge, outcome expectancies, and normative beliefs as determinants of cessation of exclusive breastfeeding: a cross-sectional study in rural Kenya. BMC Public Health. 2016;16:243.

36. Bayissa ZB, Gelaw BK, Geletaw A, Abdella A. Chinasho B, Alemayehu a, et al. knowledge and practice of mothers towards exclusive breastfeeding and its associated factors in ambo Woreda west Shoa zone Oromia region, Ethiopia. European Journal of Pharmaceutical and Medical Research. 2015; 2(2):1-13.

37. Wana AD. Assessment of knowledge, attitude, and practice on exclusive breastfeeding of child bearing mothers in Boditi town, Southern Ethiopia: A cross-sectional study. Journal of Biology, Agriculture and Healthcare 2017, 7:1.

38. Ballo TH, Wodajo MZ, Malar JS. Knowledge, attitude, and practices of exclusive breastfeeding: a facility-based study in Addis Ababa. International Journal of Therapeutic Applications. 2016;33:72-82.

39. Tadele N, Habta F, Akmel D, Deges E. Knowledge, attitude, and practice towards exclusive breastfeeding among lactating mothers in Mizan Aman town. Southwestern Ethiopia: Descriptive cross-sectional study Int Breastfeed J. 2016;11:3

40. Warillea EB, Onyango FE, Osano B. Knowledge and practice of exclusive breastfeeding among women with children aged between 9 and 12 months in Al-Sabah children hospital, juba. South Sudan South Sudan Medical Journal. 2017;10:1.

41. Shirima R, Gebre-Medhin M, Greiner T. Information and socioeconomic factors associated with early breastfeeding practices in rural and urban Morogoro, Tanzania. Acta Paediatr. 2001;90:936-42.

42. Macías YF, Glasauer P. Guidelines for assessing nutrition related knowledge, attitudes, and practices: food and agricultural organisation of the United Nations; Rome; 2014

43. Vieira TO, Vieira GO, Giugliani ERJ, Mendes CMC, Martins CC, Silva LR. Determinants of breastfeeding initiation within the first hour of life in a Brazilian population: a cross-sectional study. BMC Public Health. 2010;10:760.

44. Cascone D, Tomassoni D, Napolitano F, Giuseppe GD. Evaluation of knowledge, attitudes, and practices about exclusive breastfeeding among women in Italy. Int J Environ Res Public Health. 2019;16:2118.

45. Bashir A, Mansoor S, Naikoo MY. Knowledge, attitude, and practices of postnatal mothers regarding breastfeeding: a cross-sectional study. International Journal of Medical Science and Public Health. 2018;7(9):725.

46. Kim TD, Chapman RS. knowledge attitude and practice about exclusive breastfeeding among women in chililab in Chilinh town Haiduong province Vietnam. Journal of Health Research 2013, 27:1.

47. Singh J, BhardwarV, Kumra A. Knowledge, attitude, and practice towards exclusive breastfeeding among lactating mothers: Descriptive cross- sectional study. International Journal of Medical and Dental Sciences 2018, 7(1):1586.

48. Swigart TM. BonvecchioA, Theodore FL, ZamudioHaas S, Villanueva-Borbolla MA, thrasher JF. Breastfeeding practices, beliefs, and social norms in lowresource communities in Mexico: insights for how to improve future promotion strategies. PLoS One. 2017;12:e0180185.

49. Ayed AAN. Knowledge, attitude, and practice regarding exclusive breastfeeding among mothers attending primary health care centers in Abha city. International Journal of Medical Science and Public Health. 2014; 3(11):1355-63.

50. Arts M, Geelhoed D, Schacht C, Prosser W, Alons C, Pedro A. Knowledge, beliefs, and practices regarding exclusive breastfeeding of infants younger than 6 months in Mozambique: a qualitative study. J Hum Lact. 2011;27(1): 25-32.

51. Kimani-Murage EW, Wekesah F, Wanjohi M, Kyobutungi C, Ezeh AC, Musoke $\mathrm{RN}$, et al. Factors affecting actualisation of the WHO breastfeeding recommendations in urban poor settings in Kenya. Matern Child Nutr. 2015: 11:314-32.

52. Monteiro JCS, Dias FA, Stefanello J, Reis MCG, Nakano AMS, GomesSponholz FA. Breastfeeding among Brazilian adolescents: practice and needs. Midwifery. 2014;30:359-63.

53. Ouyang YQ, Su M, Redding SR. A survey on difficulties and desires of breastfeeding women in Wuhan, China. Midwifery. 2016;37:19-24.

54. Yadav DK, Gupta N, Shrestha N. Infant and young child feeding practices among mothers in rural areas of Mahottari district of Nepal. J-GMC-N. 2013; 6(2):29-31.

55. Col Jain S, Col Thapar RK, Brig Gupta R.K. Complete coverage and covering completely: breastfeeding and complementary feeding: knowledge, attitude, and practices of mothers. Med J Armed Forces India 2018, 74:28-32.

56. HailemariamTW, Adeba E, Sufa A. Predictors of early breastfeeding initiation among mothers of children under 24 months of age in rural part of West Ethiopia. BMC Public Health 2015, 15:1076.

57. Hanafi MI, Shalaby SAH, Falatah N, El-Ammari H. Impact of health education on knowledge of, attitude to and practice of breastfeeding among women attending primary health care centres in Almadinah Almunawwarah, Kingdom of Saudi Arabia: controlled pre-post study. J Taibah Univ Med Sci. 2014;9(3):187-93.

\section{Publisher's Note}

Springer Nature remains neutral with regard to jurisdictional claims in published maps and institutional affiliations.

Ready to submit your research? Choose BMC and benefit from

- fast, convenient online submission

- thorough peer review by experienced researchers in your field

- rapid publication on acceptance

- support for research data, including large and complex data types

- gold Open Access which fosters wider collaboration and increased citations

- maximum visibility for your research: over $100 \mathrm{M}$ website views per year

At $\mathrm{BMC}$, research is always in progress.

Learn more biomedcentral.com/submissions 